\title{
ASPECTOS \\ DA PRÁTICA DOCENTE \\ NA REVISÃO \\ E REESCRITA DE \\ NARRATIVA \\ DE TERROR
}

\section{ASPECTOS DE LA PRÁCTICA DOCENTE EN LA REVISIÓN Y REESCRITURA DE NARRATIVA DE TERROR}

\author{
ASPECTS OF THE TEACHING PRACTICE IN THE HORROR NARRATIVE'S REVISION AND \\ REWRITING
}

\author{
Denise Moreira Gasparotto* \\ Instituto Federal Catarinense \\ Renilson José Menegassi** \\ Universidade Estadual de Maringá
}

RESUMO: Este texto enfoca a revisão e a reescrita de textos na prática docente junto a alunos de $4^{\circ}$ e $5^{\circ}$ anos do Ensino Fundamental I, na região Noroeste do estado do Paraná, a partir da produção, em sala de aula, do gênero discursivo Narrativa de Terror. Concebendo a reescrita como trabalho e pautados nos pressupostos dialógicos do Círculo de Bakhtin, no tocante ao dialogismo, a responsividade do discurso escrito, aos gêneros, e em trabalhos sobre revisão e reescrita de textos, a partir dos estudos da Linguística Aplicada, a pesquisa observou a prática orientada de uma professora sobre os processos de revisão e reescrita de textos de alunos nessa situação. A caracterização do gênero Narrativa de Terror foi o foco principal, demonstrando que os apontamentos para reescrita deveriam ser observados a partir desse pressuposto. A coleta de registros ocorreu no período do segundo semestre de 2012 , após intervenção teórico-metodológica colaborativa realizada com a professora, oferecendo-lhe subsídios teóricos e discussões

\footnotetext{
* Mestre em Letras pela UEM e professora EBTT no Instituto Federal de Catarinense, campus Videira. E-mail:

denisegasparotto@yahoo.com.br 
orientadas para subsidiar a compreensão da proposta de trabalho e avaliação das condutas em andamento. Os resultados das análises apontam que: a) a internalização de pressupostos teórico-metodológicos se efetiva quando um só gênero discursivo é enfocado; b) as orientações e o acompanhamento com a docente são práticas necessárias no processo de formação continuada; c) o aprimoramento no desenvolvimento da escrita dos alunos; d) a necessidade de desenvolver e aprimorar estratégias próprias de revisão e reescrita ao gênero investigado; e) o trabalho com a revisão e a reescrita de textos em gênero textual específico se mostra mais eficaz, em virtude das necessidades desse enunciado.

PALAVRAS-CHAVE: Narrativa de terror; reescrita; formação docente continuada.

RESUMEN: Este texto enfoca la revisión y la reescritura de textos en la práctica docente junto a alumnos de los $4^{\circ}$ y $5^{\circ}$ años de Enseñanza Fundamental I, en la región Noroeste del estado de Paraná- Brasil, a partir de la producción, en el aula, del género discursivo Narrativa de Terror. Concibiendo la reescritura como trabajo y pautados en los presupuestos dialógicos del Círculo de Bakhtin, en lo que se refiere al dialogismo, la respuestas del discurso escrito, a los géneros, y en trabajos sobre revisión y reescritura de textos, a partir de los estudios de la Lingüística Aplicada, la investigación observó la práctica orientada de una profesora sobre los procesos de revisión y reescritura de textos de alumnos en ese trabajo. La característica del género Narrativa de Terror fue el foco principal, demostrando que las directrices para la reescritura deberían ser observadas a partir de esa teoría. La colecta de los registros ocurrió durante el segundo semestre de 2012, luego de la intervención teórica-metodológica colaborativa realizada con la profesora, ofreciéndole subsidios teóricos y orientaciones para apoyar la comprensión de la propuesta de trabajo y evaluación de las conductas en desarrollo. Los resultados de los análisis apuntan que: a) la internalización de presupuestos teórico-metodológicos se efectiva cuando un único género discursivo es enfocado; b) las orientaciones y el acompañamiento con la docente son prácticas necesarias en el proceso de formación continuada; c) existe la mejora en el desarrollo de la práctica escrita de los alumnos; d) la necesidad de desarrollar y mejorar estrategias propias de revisión y reescritura en relación al género investigado; e) el trabajo con la revisión y la reescritura de textos en género textual específico se muestra más eficaz, en virtud de las necesidades de ese enunciado.

PALABRAS CLAVE: narrativa de terror; reescritura; formación docente continuada.

ABSTRACT: This study was focused on recension and rewriting in teacher's practice with students of the $4^{\text {th }}$ and $5^{\text {th }}$ grades of an elementary school in the Northwest region of Paraná State, Brazil, considering the writing pieces made in class about the Horror Story discursive genre. Conceiving rewriting as work, and based on Bakhtin's Circle of dialogic assumptions concerning dialogism, the responsiveness of the written discourse, genres, and in studies on Applied Linguistics about text revision and rewriting, we observed the guided practice of a teacher on the text revision and rewriting processes of students in this situation. The characterization of the Horror Story genre was our main focus, proving that the notes on rewriting should be observed from this assumption. The records collection was carried out during the second half of the year 2012, after a collaborative theoreticalmethodological intervention with the teacher, providing theoretical subsidies and guided discussions in order to subsidize the work's proposed comprehension, and evaluate the ongoing actions. The results proved that: a) the internalization of the theoreticalmethodological assumptions happens when a single discursive genre is into focus; $b$ ) the guidance and the attendance by the teacher are necessary for the formation process; c) an improvement was observed in the students' writings; d) there is a necessity of development and improvement of proper revision and rewriting strategies towards the analyzed genre; and e) the work done with text revision and rewriting in this specific textual genre seemed to be more effective due to the necessities arising from this enunciation.

KEYWORDS: horror story; rewriting; continued teaching formation.

\section{CONSIDERAÇÕES INICIAIS}

Este trabalho ampara-se na Linguística da Enunciação, numa concepção dialógica de língua fundamentada pela Análise Dialógica do Discurso, a partir da perspectiva da Linguística Aplicada, tendo como base os pressupostos teóricos do Circulo de Bakhtin e as pesquisas desenvolvidas no Brasil sob este escopo teórico.

Consideramos que o ensino da habilidade de escrita, sobretudo na disciplina de língua materna, é sempre um desafio a ser enfrentado pelo professor, qualquer que seja o nível de aprendizagem. A escrita é individual, embora sua expressão sempre revele 
um caráter social, marcado por outras vozes (BAKHTIN, 2010). Assim, cada aluno possui um ritmo de aprendizagem, uma forma de conceber a escrita, facilidades e dificuldades próprias, o que torna a necessidade de um ensino cada vez mais singular, em meio à homogeneidade imposta pelo sistema e à sobreposição de uma série de outros fatores que vão além da simples vontade de ensinar por parte do professor.

Como ressaltado por Leal (2003), na escola, é comum que o aluno escreva para ser corrigido e não para ser lido. Esse hábito prejudica o processo interativo e anula a possibilidade de atitudes responsivas pertinentes, já que o aluno espera receber seu texto com nada além de um visto do professor, certificando que a atividade foi realizada (MENEGASSI, 2010).

Ter uma concepção definida de linguagem e de escrita é o primeiro passo para se organizar um trabalho coerente com os alunos. Neste estudo, assim como em Garcez (1998), entende-se a linguagem como construção social, em que a dialogia, sua instância superior, e a interação são elementos fundadores. Nessa mesma perspectiva, apoia-se em Sercundes (1997), Fiad e Marynk-Sabinson (1991) e Menegassi (2010), que apontam a escrita como um trabalho contínuo, em que a primeira versão de um texto nunca é um produto acabado, meramente entregue para avaliação do professor, mas sempre o resultado de reflexões, revisões, releituras e reescritas, num processo co-participativo entre professor e aluno. Desse modo, o domínio de habilidades de escrita, assim como o trabalho de reflexão sobre sua construção, não pode ocorrer senão por meio da interação social. Sob essa ótica, Geraldi (1996) considera o texto como o meio caminho traçado entre autor e leitor, através do qual as significações se constroem, determinando, a partir de Bakhtin [Volochinov] (2009), que o texto é o lugar da interação.

Ao pensar a escrita como uma forma de interação social que estabelece pontes entre o locutor/autor e o outro/leitor, ainda que esta não seja imediata, e compreendê-la como um trabalho que está sempre em processo, desenvolveu-se este estudo acerca da revisão e reescrita de textos em situação de ensino, especificamente voltada para o gênero Narrativa de Terror. O trabalho enfoca a prática de uma professora de Língua Portuguesa junto a seus alunos de $4^{\circ}$ e $5^{\circ}$ anos do Ensino Fundamental I, na região Noroeste do estado do Paraná, a partir da produção, em sala de aula, do gênero eleito. Embora o trabalho tenha sido desenvolvido nas duas turmas, aqui, ateve-se unicamente àquele desenvolvido com os alunos do $4^{\circ}$ ano, como mostra analítica de toda a pesquisa.

A partir de encontros de orientação teórico-metodológica sobre o trabalho de produção, revisão e reescrita de textos, acompanhouse a prática dessa professora no desenvolvimento de uma unidade de ensino voltada para o gênero Narrativa de Terror. O trabalho culminou em duas produções de narrativas por cada aluno, seguidas por revisão da professora, por meio de apontamentos e comentários escritos, e reescrita pelos alunos.

Nesse processo, a caracterização do gênero textual Narrativa de Terror foi o foco de trabalho, demonstrando que os apontamentos para reescrita deveriam ser observados a partir desse pressuposto. A coleta de registros ocorreu no segundo semestre de 2012, por meio de gravação em áudio dos encontros de estudo teórico-metodológico da pesquisadora com a professora e pela digitalização de todo material escrito e produzido pelos alunos.

\section{FUNDAMENTOS TEÓRICOS DA ADD}

As discussões do Circulo de Bakhtin são fonte de interpretações distintas e de aplicação em estudos de diversas áreas de conhecimento. No Brasil, a leitura desse conjunto de obras gerou o aprofundamento de estudos voltados para a dialogia constitutiva da linguagem. Passou-se, desse modo, a partir de discussões propostas por Brait (2006, 2012), a chamar essa vertente de Análise Dialógica do Discurso, em que se apresenta a interação verbal como a categoria fundante da linguagem.

Nessa perspectiva, não há enunciado isolado, pois cada um constitui-se num elo de uma cadeia e, por esse motivo, só pode ser compreendido em seu conjunto. Cada enunciado está estreitamente ligado aos que o antecedem e aos que o sucedem, o que o faz ser concreto. O enunciado concreto, obtido através do diálogo histórico entre eu e o outro, organiza-se, e tendo uma função social, constitui os gêneros do discurso (BAKHTIN, 2010), pois, como ressaltam Rodrigues e Acosta-Pereira (2010), há de se considerar os gêneros em sua dimensão social e verbo-visual. Entende-se, desse modo, que para a Análise Dialógica do Discurso o social constitui

Gasparotto \& Menegassi I Aspects da prática docente na revisão e reescrita de narrativa de terror 
o individual. Assim, na leitura de Brait (2006), a proposta do Círculo para o estudo do discurso vai além da materialidade linguística, articulando concomitantemente o interno e o externo da linguagem. "O enfrentamento bakhtiniano da linguagem leva em conta, portanto, as particularidades discursivas que apontam para contextos mais amplos, para um extralinguístico aí incluído [...]” (BRAIT, 2006, p. 13).

Esse percurso metodológico, conforme Acosta-Pereira (2011), não permite o uso de categorias a priori que sejam sistematicamente aplicadas aos textos. Para o autor, há uma construção de movimentos teórico-metodológicos multifacetados que, em sua totalidade, apontam caminhos a serem percorridos pelo pesquisador. Assim, é o não estabelecimento de categorias fixas de análise que revela um posicionamento dialógico em relação ao que está sendo estudado. Parte-se, por exemplo, do entendimento do gênero discursivo e de sua importância para a interação. Dessa forma, a partir da visão dialógica assumida neste estudo, buscamos, sobretudo na interação verbal entre professor e aluno no momento da produção textual, evidências linguístico-discursivas que nos levassem ao reconhecimento de uma metodologia de correção do gênero textual Narrativa de Terror, para permitir a compreensão de como o trabalho docente de revisão textual se efetua adequadamente na reescrita do aluno.

\subsection{Interação verbal e produção de textos na escola}

Por meio da visão dialógica de linguagem proposta pelo Círculo, entende-se que a constituição do sujeito se estabelece a partir de sua relação com o outro, via gêneros discursivos. Assim, como posto por Bakhtin [Volochinov] (2009), o discurso é um território comum entre o outro e mim, pois ele sempre parte de alguém, um locutor, para se dirigir ao outro. Dessa mesma forma, o ouvinte pode tomar a palavra e se dirigir a mim, que, ao ouvir, torno-me o outro. Nas palavras de Geraldi (1996, p.139), "[...] é por isso que na 'minha' palavra me (re)velo na contrapalavra do outro que me constitui como sujeito". Essa relação de alteridade, marcada por sujeitos sócio, histórico e ideologicamente constituídos e pela situação concreta, dá vida ao processo de interação verbal, apontado por Bakhtin [Volochinov] (2009) como a base de toda compreensão comunicativa.

No tocante à interação por meio da escrita, Antunes (2003) explica-nos que se trata de outra modalidade de interação verbal, em que a recepção é adiada, pois os sujeitos atuantes não ocupam, ao mesmo tempo, o mesmo espaço. Logo, a interação não pressupõe dois indivíduos reais, espacialmente situados. Seu caráter cultural, social, histórico e ideológico dá espaço ao diálogo por meio de uma representação. No caso da escrita, o texto é o lugar da interação. Na situação escolar de produção de textos, o processo de interação efetiva-se pela alteridade discursiva entre professor e aluno, sendo que o discurso do professor é construído com base no texto do aluno, por meio de seus apontamentos e comentários de revisão.

A partir de Bakhtin [Volochinov] (2009), depreende-se que há várias formas de interação, dentre elas aqui interessa: entre dois indivíduos, do indivíduo consigo próprio e do indivíduo com o escrito. Ao pensar a interação verbal por meio do discurso escrito e, ainda, relacionar essa forma de expressão com a prática de produção de textos na escola, tendo como ponto de partida a concepção de escrita como trabalho (SERCUNDES, 1997; FIAD; MARYNK-SABINSON, 1991; MENEGASSI, 2010), nota-se que esse processo interativo pode contribuir significativamente para o desempenho do estudante. É, pois, na interação do indivíduo consigo mesmo, com seu texto e com o professor, que se desenvolvem as habilidades discursivas. O grande desafio está, porém, em levar o aluno a esse diálogo com o escrito, que precisa ser consciente, para que ele se reconheça como sujeito de seu próprio discurso. Se esse espaço de interação é tido via texto, é possível também afirmar que, no trabalho com a escrita, o professor é quem media esse processo. Não se trata apenas de tomar o texto de um aluno e apontar-lhe o que demanda correções. Mais do que isso, é fundamental que o professor tenha consciência de seu diálogo por meio do escrito, pois um apontamento mal formulado pode interromper o diálogo se o aluno não o compreender. Além disso, a abordagem adotada pelo professor para fazer seus apontamentos pode levar a diferentes níveis de interação do aluno com o escrito, o que certamente marcará a qualidade de sua reescrita, isto é, a qualidade de sua responsividade, nos termos bakhtinianos.

A interação verbal na produção textual escolar envolve, portanto, diferentes processos interativos: a) do aluno com seu texto; b) do professor com o texto do aluno; c) do aluno com os apontamentos deixados pelo professor na revisão; d) novamente, do aluno com 
seu texto. Cada um desses processos deve, ainda, necessariamente, considerar aspectos como a finalidade, o interlocutor, o gênero e o suporte, que servem de base para a escolha do estilo a ser utilizado no discurso (MENEGASSI, 2012).

Sobre essas múltiplas relações que engendram a interação, Geraldi (1996, p.21) salienta que

Aceitar a interação verbal como fundante do processo pedagógico é deslocar-se continuamente de planejamentos rígidos para programas de estudos elaborados no decorrer do próprio processo de ensino aprendizagem. Programas de estudos não implicam espontaneísmo, ao contrário, exigem trabalho rigoroso e constante, demandam tempo e dedicação.

Desse modo, voltando-se para as práticas de escrita em sala de aula, compreende-se que há, no texto, um espaço para o diálogo que precisa ser explorado pelo professor de diferentes formas, conforme as necessidades de cada aluno, sempre tendo em vista a finalidade superior de todo o trabalho: proporcionar ao aluno a oportunidade de reconhecer-se como sujeito de seu discurso, como produtor de textos capaz de interagir não apenas com o professor, mas com seu próprio discurso, levando em conta o seu objetivo comunicativo. O trabalho com escrita e reescrita que considera o desenvolvimento do aluno como sujeito proporciona o desenvolvimento da consciência discursiva pela linguagem, que possivelmente estende-se ao desenvolvimento do sujeito como um ser social, capaz de agir, argumentar, refletir sobre si e sobre o outro/interlocutor nas diversas situações cotidianas. Nessa perspectiva, a produção de textos de ser um exercício unicamente escolar de prática escrita, pois provoca o aluno em todo seu agir discursivo.

\subsection{A reescrita no processo de interação}

A reescrita de textos ainda não é uma prática comum em ambiente escolar. Contudo, é cada vez mais evidente a necessidade de sua inserção no plano de trabalho docente, sobretudo, com as disciplinas de ensino de línguas. Geralmente, os alunos escrevem textos e os entregam para o professor, cientes de que aquele é o fim de um processo, pois depois disso somente receberão o texto com correções resolutivas ou um visto do professor, certificando que anotou em seu diário que o aluno produziu o texto. Não há dúvidas, porém, de que tal abordagem é inócua e, de forma alguma, promove o desenvolvimento de habilidades discursivas pelo aluno.

Ter uma concepção de língua como uma construção social, em que sua modalidade escrita se destaca como um trabalho a ser desenvolvido e refletido nas suas mais diversas etapas, implica pensar a prática da reescrita como inerente ao trabalho de revisão por parte do professor e imprescindível para que o aluno interaja em níveis cada vez maiores com seu próprio discurso. Ao partilhar dessas mesmas concepções, Menegassi (1998) defende que a reescrita deve ser considerada, por professores e alunos, uma atividade necessária e contínua. O autor completa que a revisão do professor é um produto, mas que sempre deve dar origem a um novo processo, que se inicia quando o aluno recebe seu texto com os apontamentos, busca compreendê-los, para, então, proceder à reescrita. A revisão do professor funciona, nesse sentido, como o ato de devolução da palavra ao sujeito.

O texto é um trabalho nunca acabado, pois possui um caráter recursivo, o que permite ao autor reformulá-lo quantas vezes julgar necessário e em qualquer momento da produção, sejam na primeira, terceira ou quarta versões. Como salienta Geraldi (1996, p. 137), o trabalho do locutor, tanto na fala como na escrita, revela "[...] um movimento contínuo e recursivo entre inter-intra-interindividual". Assim, é a qualidade da interação aluno-texto-professor, e vice-versa, que permitirá que o texto chegue a esse nível.

De acordo com Ruiz (2010), a partir de estudos em Linguística Aplicada a reescrita pode acontecer de diferentes formas: individual, sem mediação do professor; coletiva; em pares; e individual mediada pelo professor. Cada uma delas exige um nível diferente de interação. Por exemplo, se em uma turma os alunos não estão habituados à prática da reescrita, é interessante propor inicialmente reescritas coletivas, em que um dos textos é projetado no quadro e toda a turma é motivada a revisá-lo e propor uma reescrita que será redigida pelo professor no quadro. A partir disso, pode-se passar à reescrita em pares, em que um colega revisa o texto do outro e sugere melhorias; ou a mediada pelo professor, em que se fazem apontamentos específicos no texto de cada aluno para que, individualmente, proceda-se à reescrita. O importante é que a interação seja mantida e que sua qualidade aumente a cada produção.

Gasparotto \& Menegassi Aspects da prática docente na revisão e reescrita de narrativa de terror 
Assim, passa-se a considerar todo o processo de produção e não apenas o seu produto. Vale destacar que, nesse estudo, a reescrita foi individual e mediada por apontamentos escritos da professora no texto dos alunos.

A reescrita, conforme Garcez (1998), marca a importância do outro no diálogo, pois ao ouvir/ler/revisar o sujeito realiza uma reflexão acerca do discurso por ele construído, interpretando e (re)significando, motivado pelos apontamentos e comentários que lhe foram deixados. Mais uma vez, evidencia-se o importante papel de revisor do professor ao requerer uma produção textual do aluno.

Ao receber seu texto com os apontamentos escritos do professor, é importante que o aluno analise-o em uma nova leitura para, então, iniciar a reescrita. Nesse movimento de tomar os apontamentos do professor e dar a eles sua própria compreensão, estabelecese um juízo de valor que leva o aluno a considerá-los ou não em sua reescrita, o que marca sua responsividade. Sobre essa etapa, Fabre (1986) explica que se trata de operações linguístico-discursivas realizadas pelo aluno e sistematiza as seguintes possibilidades de atitude do aluno no momento da reescrita:

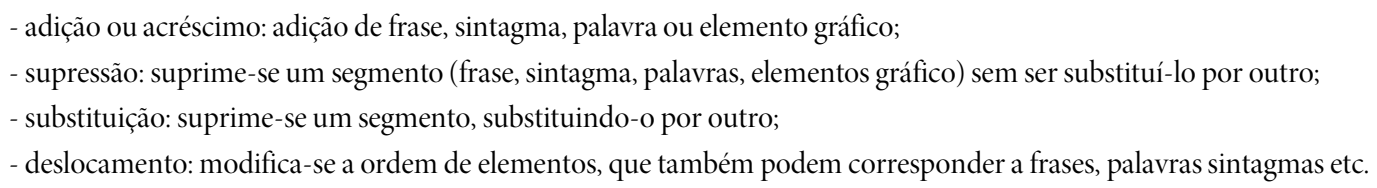

Normalmente, as operações utilizadas pelo aluno estão relacionadas à revisão adotada pelo professor. Num texto em que predominam correções resolutivas, por exemplo, é comum a predominância da substituição, pois o trabalho é de visualizar a correção deixada pelo professor e colocá-la no lugar do trecho com problemas.

No trabalho de Fabre (1986), que analisou textos de alunos entre 6 e 7 anos durante um ano letivo, os resultados apontaram maior uso da supressão e menor uso do acréscimo. Já o trabalho conduzido por Menegassi (1998), que analisou textos de alunos do primeiro ano da graduação em Letras da Universidade Estadual de Maringá, mostrou que, das 92 sugestões atendidas pelo grupo de alunos, 53 foram de substituição e apenas 3 foram de deslocamento.

Menegassi (1998), corroborando os pressupostos de Fabre (1986), aponta quatro estratégias que podem ser utilizadas pelo aluno por meio das operações linguístico-discursivas:

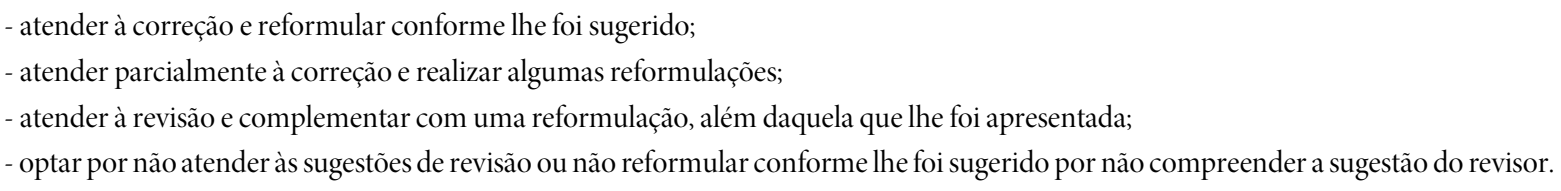

A partir dessas ações, obtidas por meio das propostas de Fabre, Menegassi (1998) propõe, ainda, uma quinta estratégia, que marca a autonomia do aluno ao revisar seu texto: apresentar reformulações que extrapolam as sugestões do revisor, isto é, o aluno relê seu texto e o reescreve indo além daquilo que lhe foi proposto na revisão;

Assim, o aluno pode não se ater estritamente à correção do professor e decidir por eliminar o trecho que lhe soa complexo para a reescrita, ou decidir ultrapassar aquilo que lhe foi requisitado, efetuando acréscimos que lhe pareçam viáveis no momento em que relê seu texto, por sua consciência envolta nessa etapa do processo da escrita.

As operações linguístico-discursivas revelam, portanto, a complexidade do trabalho de reescrita de textos e a necessidade de se utilizar metodologias específicas que efetivamente levem o aluno à reflexão.

Como destaca Geraldi (1996), em cada texto o trabalho discursivo não é simplesmente retomado em seu significado original, pois as expressões se ressignificam e se modificam. Assim também acontece com cada revisão. A recursividade da escrita faz da reescrita um momento para além da releitura, que pode resultar em novos acréscimos, novos sentidos etc. 


\subsection{A reescrita a partir do gênero textual}

Ao compreender o complexo processo de interação implícito em um texto reescrito, compreende-se também que os encaminhamentos dados ao aluno levam em conta aspectos essenciais para a construção do texto. O gênero está entre um dos aspectos mais relevantes a serem considerados, pois sua estruturação é toda marcada pelo estilo de linguagem utilizado. Para Garcez (1998, p. 62), "[...] o gênero mediatiza a atividade, dá-lhe forma e materialidade. Ao mesmo tempo em que o indivíduo se apropria desses instrumentos mediadores, apropria-se também dos seus esquemas de utilização”. A partir do que aponta a autora, é possível afirmar que, também nos apontamentos de revisão que orientam a reescrita, é necessário ter o gênero como ponto de partida.

Embora não tragam orientação alguma sobre como esse processo deve ser realizado, os Parâmetros Curriculares Nacionais (BRASIL, 1998) alertam para a importância de se considerar elementos próprios do gênero trabalhado ao orientar o aluno para a reescrita. Fuza e Menegassi (2012) também percebem essa importante relação e, em um estudo sobre a metodologia de revisão escrita adotada por um professor nas narrativas infantis de seus alunos, percebem que, embora sejam usados bilhetes-textuais, nenhum deles contemplava aspectos próprios do gênero.

Apontamentos referentes ao gênero textual trabalhado podem abarcar diferentes elementos considerados fundamentais ao se revisar um texto. A partir do gênero marca-se o interlocutor, define-se o estilo, enfim, cumpre-se um objetivo comunicativo. Antunes (2003) destaca que os gêneros evidenciam a natureza complexa das relações linguísticas, pois são, ao mesmo tempo, mutáveis e prototípicos.

O que se propõe aqui é que as considerações relacionadas à prototipicidade, e até mesmo à mutabilidade do gênero, podem nortear o aluno para a reescrita. Não se trata de oferecer orientações meramente estruturais, mas considerar o gênero em seus três elementos: tema, organização composicional e estilo (BAKHTIN, 2010), fazendo com que o exercício da reescrita seja também uma forma de apropriação do gênero trabalhado.

\subsection{O gênero discursivo Narrativa de Terror}

Os gêneros do discurso são enunciados relativamente estáveis que atendem a condições enunciativas reais e finalidades comunicativas específicas. Como propõe Bakhtin (2010), os gêneros são constituídos por seu conteúdo temático, construção composicional e estilo. Eles são a concretização de nossas atividades de linguagem. Como este estudo se propõe à apresentação de um trabalho de reescrita direcionado ao gênero Narrativa de Terror, destacam-se, a seguir, suas principais características. Assim, para Garcia (2007, p. 258),

Toda narrativa consiste numa sequência de fatos, ações ou situações que, envolvendo participação de personagens, se desenrolam em determinado lugar e momento, durante certo tempo. As circunstâncias e motivações da atuação das personagens e a configuração dos seus conflitos e antagonismos constituem situações dramáticas.

Sob este viés, Costa (2007) pontua que um dos pontos de distinção entre as narrativas é a sua temática, que pode envolver: aventura, sentimentos infantis, relações familiares, questões históricas e sociais, terror etc. Assim, o que marca cada narrativa infantil é o modo como cada tema é tratado.

A temática do terror, por sua vez, leva à produção de um enredo, comumente, com personagens fantásticos em um lugar assustador. Tem-se, portanto, bruxas em castelos abandonados, vampiros em cemitérios, fantasmas na escuridão etc. No entanto, a narrativa também pode apresentar personagens reais que passam por situação medo, como sair da escola e ser perseguido por alguém. Além 
dos personagens, a descrição do espaço também pode incrementar e trazer mais suspense à história. Esses aspectos que incorporam a temática fazem parte da organização composicional do gênero.

No tocante ao estilo, destacam-se a predominância de verbos no pretérito perfeito, as escolhas lexicais próprias da temática, o uso de interjeições, como, por exemplo, para expressar barulhos misteriosos ou as expressões de espanto dos personagens. Além dos personagens, a descrição do espaço também pode incrementar e trazer mais suspense à história.

Quanto ao desfecho, este pode ser trágico ou feliz. As Narrativas de Terror variam entre finais fatais e aqueles em que os personagens do bem conseguem derrotar o mal, ou percebem que aquele não era um motivo para se ter medo.

\section{DO ESTUDO TEÓRICO ÀS REESCRITAS}

A coleta de registros foi realizada no ano de 2012, em uma turma de 26 alunos do $4^{\circ}$ ano do Ensino Fundamental de uma escola municipal de Terra Rica, Noroeste do Paraná. As atividades foram todas desenvolvidas pela professora Ana, que na época ministrava três vezes por semana Língua Portuguesa aos alunos. Além de Pedagogia, Ana possui formação em Letras e cursou o Magistério concomitantemente ao Ensino Médio. Em 2012, atuou no município e também em turmas de Ensino Médio e no curso de Formação de Docentes, como professora contratada por tempo determinado pelo estado.

Os registros gerados e coletados durante o processo de realização deste trabalho foram: e-mails entre a pesquisadora e a professora; gravações em áudio dos encontros da pesquisadora com a professora; atividades prévias desenvolvidas com os alunos em sala de aula; produções textuais dos alunos.

O cronograma de trabalho foi elaborado com base nos horários de disponibilidade da professora. As atividades consistiram basicamente em três etapas: a) encontros de estudos teóricos e elaboração da unidade de ensino com a professora; b) aplicação da unidade de ensino em sala de aula, pela professora, e encontros de orientação com a pesquisadora; c) organização e lançamento da coletânea com os alunos.

O percurso iniciou-se com encontros de estudos teóricos entre a pesquisadora e a professora. Para esse estudo, foi organizada uma apostila contendo textos que visavam ao conhecimento desde as concepções de escrita até a metodologia de correção de textos, finalizando com sua organização a partir do gênero Narrativa de Terror.

Para cada texto, elaborou-se uma apresentação, informando sua referência e a temática abordada. Também foram elaborados roteiros de leitura, em forma de perguntas, colocados ao final de cada texto. As perguntas do roteiro de leitura tinham a finalidade de promover reflexão sobre o texto lido e possibilidade de relacioná-lo com a prática da professora. O material abordou desde a concepção de escrita até o trabalho de revisão textual pelo professor ${ }^{1}$.

Esses textos foram lidos durante o mês de agosto e discutidos em encontro entre a professora e a pesquisadora. Nesse encontro, foram levadas narrativas de alunos de $5^{\circ}$ ano, já corrigidas, que foram analisadas juntamente com a professora, a fim de perceber os apontamentos próprios do gênero e também a resposta dos alunos na reescrita. Esses textos foram retirados do trabalho de Esper (2012).

Após esse estudo, passou-se à fase de preparação, junto à professora, da unidade de ensino voltada para o gênero Narrativa de Terror. As atividades prévias de leitura e escrita foram construídas com base na história O defunto que devia, de Ângela Lago. Foram elencadas também várias outras histórias contadas pela professora no decorrer das aulas.

\footnotetext{
${ }^{1}$ No material, constam os textos de: a) Menegassi (2010), que discute as diversas concepções de escrita, relacionando-as às concepções de linguagem; b) Garcez (1998), uma apresentação dos conceitos que se aproximam nas teorias de Vygotsky e Bakhtin; c) Menegassi (1998) e Moterani (2012), sobre as operações linguístico-discursivas de construção textual; e d) Ruiz (2010), com metodologias de correção de textos.
} 
Durante a aplicação da unidade de ensino pela professora, a pesquisadora manteve contato por e-mail, questionando sobre os êxitos, dificuldades com as atividades ou com o cumprimento do cronograma.

O primeiro texto foi produzido pelos alunos após duas semanas de atividades e de leitura de histórias. Antes dessa primeira produção, a professora trabalhou com os alunos o texto "Receita para Narrativa de Terror", que, de forma lúdica, instrui sobre todos os elementos que devem fazer parte de uma história do gênero, como lugares assustadores e personagens monstruosos, apresentação de acontecimentos inexplicáveis, momentos de hesitação, arrepios etc.

Quando os alunos produziram o primeiro texto, solicitou-se à professora que entregasse alguns textos de alunos com diferentes níveis de habilidades com a escrita. A pesquisadora corrigiu os três textos que a professora entregou e os devolveu, pedindo que observasse aqueles apontamentos ao corrigir os textos dos demais alunos. Esta foi uma medida para nortear a primeira correção de Ana a partir do gênero textual abordado. Feita a revisão, a professora encaminhou os alunos à reescrita.

As atividades preparadas para dar continuidade ao trabalho e encaminhar a segunda produção escrita foram relacionadas aos medos. Após contar uma história de um personagem que falava sobre seus medos, os alunos escreveram em uma folha avulsa o maior medo que tinham e qual seria o antídoto para combater esse medo. Após essa atividade e a resolução de exercícios sobre pontuação organizados por Ana, os alunos foram motivados a produzir uma nova narrativa.

Para nortear a segunda revisão escrita da professora, foi enviada, por e-mail, uma lista com aspectos que deveriam ser considerados ao se propor a reescrita daquele gênero. Depois disso, a professora encaminhou novamente os textos para a reescrita. Apresenta-se, aqui, a parte do e-mail em que a pesquisadora reforça as instruções dadas à docente.

Oi Ana, $[\ldots]$

Como não tivemos muito tempo para analisar as correções, reforço para você algumas coisas que decidimos para você sempre as considere no momento de fazer os apontamentos:

- o foco da correção será o conteúdo, que será avaliado conforme as especificidades do gênero. É muito importante que atentemos para as características da narrativa de terror, além de outros desvios de conteúdo que o texto possa apresentar. Então, coloco aqui novamente as perguntas que você apresentou aos alunos antes da produção. Acho que, na correção, você pode se basear nelas, observando as que foram ou não atendidas pelo aluno. Também seria legal você retomar essas perguntas com eles antes de fazerem a segunda produção.

- Que personagens vão fazer parte da sua história? Como elas serão?

- Qual será a sequência de acontecimentos que você vai narrar?

- Como será o cenário onde os fatos acontecerão?

- Você vai criar um clima de suspense ou de humor? Que elementos vão usar para isso?

- Em quanto tempo acontecerá a história?

- Opções de títulos para o texto.

- Autor.

- Conforme você julgar necessário, vá corrigindo os aspectos ortográficos.

As atividades que seguiram o trabalho foram relacionadas à escolha dos textos e preparação de uma coletânea de textos que contivesse um texto de cada aluno. A professora organizou concursos para o título e a capa do livro; também solicitou aos alunos que escolhessem qual texto gostariam que fizesse parte do livro. Nessa fase, algumas reescritas foram feitas, a fim de adequar melhor alguns textos que ainda apresentavam muitos desvios. 


\section{A REESCRITA DO GÊNERO NARRATIVA DE TERROR}

Como a proposta aqui é apresentar o trabalho docente na correção do gênero Narrativa de Terror a partir das especificidades do gênero, foi preciso estabelecer alguns critérios que norteassem a contagem e a análise dos registros. Essas categorias foram construídas a partir dos encontros de estudos teóricos e das ocorrências de apontamentos utilizados pela professora.

\subsection{Escolhas metodológicas}

Foram coletados textos de 26 alunos, mas para esse estudo foram selecionados apenas os textos dos alunos que participaram das duas produções textuais e que fizeram pelo menos uma reescrita de cada uma delas. Foram desconsiderados também os textos dos três alunos cuja correção do primeiro texto foi feita pela pesquisadora, como orientação à professora. Assim, foram analisados os textos de 19 alunos, considerando a primeira e a segunda versão, visto que somente alguns alunos chegaram a produzir a terceira versão.

Quanto à análise dos apontamentos deixados pela docente, optou-se por contabilizar uma parte deles, desconsiderando as ocorrências de correção indicativa ou resolutiva. Essa escolha se justificou pelo fato de que as ocorrências de correção resolutiva e indicativa foram todas voltadas para problemas ortográficos, que, no momento, não nos interessam para a análise do gênero, já que são aspectos da língua em geral.

Desse modo, observaram-se os apontamentos classificatórios e os bilhetes-textuais (RUIZ, 2010). A partir desses, procurou-se identificar e analisar aqueles que se referiam especificamente ao gênero Narrativa de Terror. Como se trata também de uma narrativa ficcional, aspectos como narrador e espaço também foram considerados apontamentos próprios do gênero.

Com base nessas considerações, chegou-se aos seguintes critérios, que classificariam um apontamento da professora como específico do gênero trabalhado:

\begin{tabular}{|c|c|}
\hline $\begin{array}{c}\text { Aspecto } \\
\text { considerado }\end{array}$ & Apontamentos e comentários da docente \\
\hline $\begin{array}{l}\text { Organização } \\
\text { composicional }\end{array}$ & $\begin{array}{l}\text { - Apresentação do espaço (ex: descrição do lugar como assustador). } \\
\text { - Narração: coerência da sequência narrativa (ex: descrição confusa dos } \\
\text { fatos, ruptura na ordenação dos fatos). } \\
\text { - Narração: marcação do narrador. }\end{array}$ \\
\hline Temática & $\begin{array}{l}\text { - Caracterização dos personagens (assustadores). } \\
\text { - Enredo: marcação da temática de terror. }\end{array}$ \\
\hline Estilo & $\begin{array}{l}\text { - Pontuação: uso do travessão e de dois pontos para introduzir a fala dos } \\
\text { personagens. } \\
\text { - Tempo verbal: uso de verbos no pretérito perfeito. } \\
\text { - Uso de elementos coesivos adequados ao narrar os acontecimentos (ex: } \\
\text { uso excessivo da conjunção "e"). }\end{array}$ \\
\hline
\end{tabular}

Quadro 1: Apontamentos e comentários do gênero 
4.2 Apontamentos da professora e respostas dos alunos na reescrita

Com o intuito de respaldar a discussão dos exemplos apresentados, elaborou-se o Quadro II, com o número de apontamentos feitos pela professora no texto de cada um dos 19 alunos que tiveram seus textos analisados. A segunda e a quarta coluna referem-se ao total de apontamentos deixados pela professora na primeira e segunda produção, respectivamente. A terceira e a última coluna apresentam a quantidade de apontamentos específicos de cada texto que se referiam ao gênero trabalhado.

\begin{tabular}{|c|c|c|c|c|}
\hline Apontamentos & Texto 1 total & $\begin{array}{l}\text { Texto } 1 \text { ref. } \\
\text { gênero }\end{array}$ & $\begin{array}{c}\text { Texto } 2 \\
\text { Total }\end{array}$ & $\begin{array}{l}\text { Texto } 2 \text { ref. } \\
\text { gênero }\end{array}$ \\
\hline Aluno A & 4 & 2 & 2 & 1 \\
\hline Aluno B & 4 & 1 & 1 & 1 \\
\hline Aluno C & 1 & 0 & 3 & 2 \\
\hline Aluno D & 3 & 1 & 3 & 3 \\
\hline Aluno E & 3 & 2 & 3 & 1 \\
\hline Aluno F & 3 & 1 & 4 & 2 \\
\hline Aluno G & 2 & 1 & 2 & 0 \\
\hline Aluno $\mathrm{H}$ & 1 & 0 & 4 & 0 \\
\hline Aluno I & 6 & 4 & 1 & 1 \\
\hline Aluno J & 1 & 0 & 5 & 2 \\
\hline Aluno K & 1 & 0 & 6 & 6 \\
\hline Aluno M & 4 & 3 & 1 & 1 \\
\hline Aluno N & 4 & 2 & 2 & 2 \\
\hline Aluno P & 2 & 2 & 1 & 1 \\
\hline Aluno Q & 6 & 1 & 1 & 1 \\
\hline Aluno R & 3 & 1 & 1 & 0 \\
\hline Aluno S & 3 & 2 & 4 & 2 \\
\hline
\end{tabular}

Quadro 2: Total de apontamentos do gênero

Portanto, foram feitos exatamente 95 apontamentos nos textos desses alunos, sendo que 49 abordaram aspectos relacionados à Narrativa de Terror, totalizando 51,57\% do todo. Esse primeiro registro já aponta que houve interesse da professora em adequar seu modo de revisão textual, atendendo às necessidades específicas do gênero. Durante a discussão do material teórico, a professora alegou que imaginava praticar a reescrita com os alunos, mas com a leitura dos textos havia percebido que sua metodologia era, na verdade, de higienização dos textos (JESUS, 2001), já que ela se atinha à correção de aspectos gramaticais. 
Na observação da revisão escrita da professora, alguns apontamentos pareciam tratar de aspectos da narrativa, porém, por sua apresentação generalizada, não os consideramos como apontamentos referentes ao gênero trabalhado. Assim, não foram considerados próprios do gênero, bilhetes como:

\section{"Sua história está muito boa, você só precisa usar melhor os sinais de pontuação [...]" "Sua história é ótima, mas você não usou os sinais de pontuação [...]"}

Esses apontamentos, embora tratem de pontuação, não abordam orientações específicas, como o uso do travessão ou de dois pontos ao introduzir fala de personagens, no gênero analisado.

Também não foram considerados específicos bilhetes que diziam que o texto estava confuso, mas não orientavam sobre a sequência da narrativa ou mostravam como o texto poderia ser melhorado.

Exporemos, aqui, a análise dos apontamentos e da reescrita das duas produções dos alunos $E$ e $P$, a fim de elucidar como o processo de reescrita do gênero foi mediado pela professora e como cada aluno respondeu aos apontamentos, por meio da primeira reescrita de cada texto. Foram selecionadas duas produções do aluno $E$ e uma produção do aluno $P$.

Na primeira produção, o aluno $E$ escreve uma narrativa intitulada $O$ Lobisomem, em que um grupo de amigos passa em frente ao cemitério, à noite, e decide entrar. Lá, passam muito medo e fogem assustados decididos a não mais voltar. Conforme o Quadro II, há nesse texto dois apontamentos deixados pela professora que orientam o gênero. Para melhor compreensão, passaremos a denominar esse apontamento de Apontamento do Gênero.

O Excerto I mostra uma pergunta que se encaixa no critério de caracterização dos personagens, já que a narrativa exige isso.

\section{Excerto I}

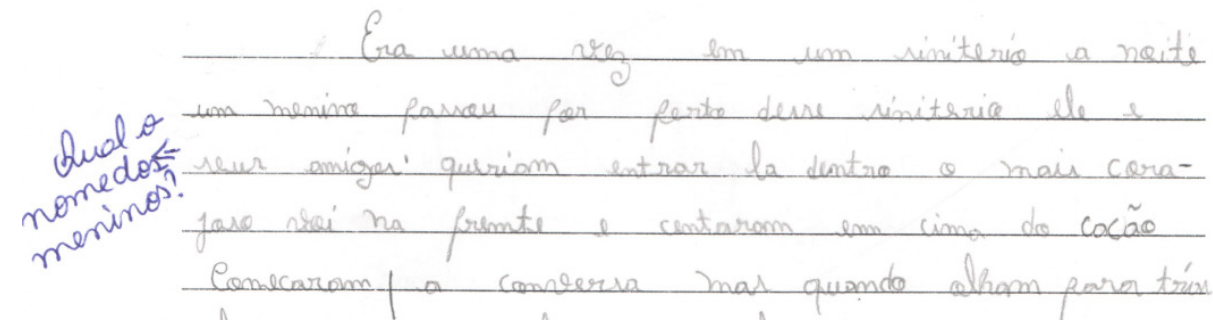

Além dos problemas de pontuação, que foram recorrentes nos textos de toda a turma, o trecho não apresenta descrição dos personagens, que é citado apenas como "um menino" e "seus amigos". Em vista disso, a professora questiona sobre o nome desses meninos, instigando à caracterização dos personagens. A resposta do aluno na reescrita é a seguinte:

\section{Excerto II:}

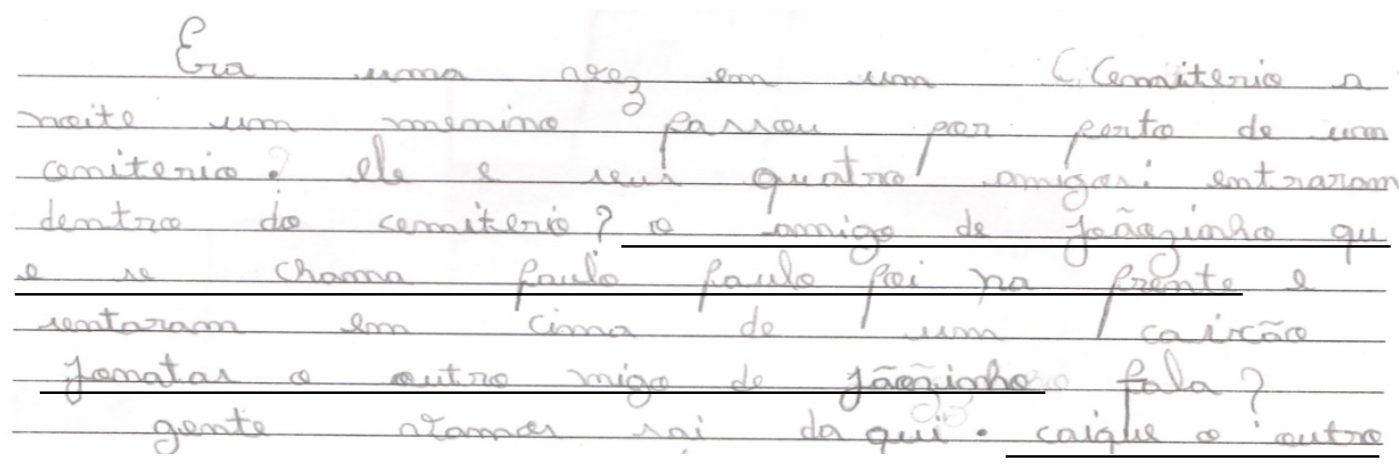


Com relação ao nome dos personagens, o aluno E procura atender o apontamento do gênero, mas seu desempenho é parcial, pois os personagens são apresentados de maneira confusa. Um aspecto relevante é que a reescrita do excerto apresenta vários sinais de pontuação utilizados incorretamente, que não haviam sido usados na primeira versão. Compreendeu-se, assim, que a formulação do aluno $E$ levou em conta outro apontamento do gênero deixado pela professora, também na margem, algumas linhas abaixo do Excerto I:

Excerto III:

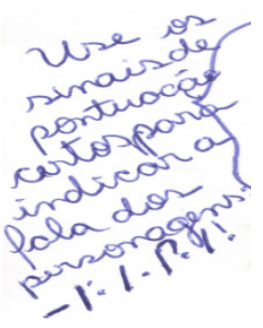

A impressão que se tem é de que o aluno observou o apontamento e acrescentou os sinais de pontuação aleatoriamente em seu texto, pois a forma como foram dispostos na reescrita revela que não há domínio desse uso. Notou-se, também, que o modo como esse bilhete foi apresentado não favoreceu a compreensão dos alunos, pois sua utilização em textos de outros alunos também não levou à reescrita adequada. Contudo, quando, em textos de outros alunos, a professora alertou para o uso do travessão na fala dos personagens e, logo em seguida, exemplificou como deveria ser feito, os alunos compreenderam seu apontamento e melhoraram a reescrita. Já se nota, portanto, que o apontamento do gênero, além de tratar das especificidades do texto trabalhado, deve levar em consideração o interlocutor/autor que receberá o texto revisado, pois o estilo escolhido pode prejudicar a interação. Para melhor compreensão, apresenta-se a seguir um bilhete deixado pela docente no texto de outro aluno, que não o aluno E, atendido pelo aluno na reescrita, tendo em vista a linguagem elucidativa que aborda.

Excerto IV:

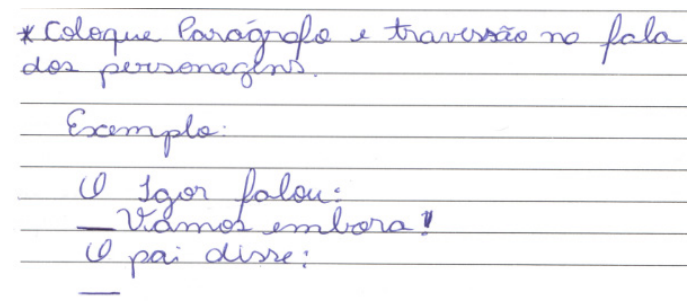

Aqui, além de mencionar o uso incorreto da pontuação, a professora orienta o aluno sobre como isso pode ser feito, aumentando o nível de interação, o que não ocorreu no comentário deixado no texto do aluno $E$. Não se trata, portanto, de tecer comentários no texto do aluno, mas de como fazê-lo, considerando o contato que esse aluno tem com a escrita, assim como seu próprio nível de aprendizagem. Como salienta Menegassi (2000), uma observação mal formulada pode tanto auxiliar quanto dificultar a construção textual.

Na segunda produção do aluno $E$, há apenas um apontamento do gênero; entretanto, sua utilização se refere a toda construção textual. Nessa etapa, o aluno produz a narrativa sobre uma rua mal assombrada e descreve todos os acontecimentos, utilizando verbos no presente, como se observa:

\section{Excerto V}

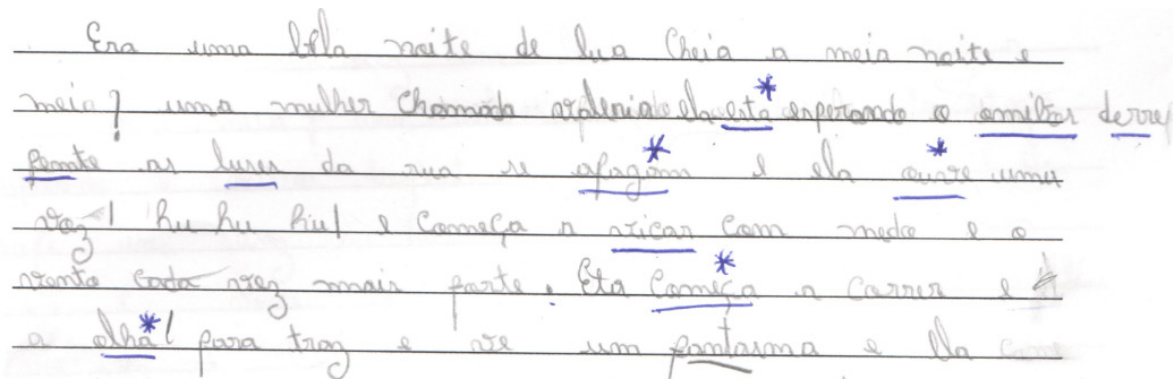


Na revisão, a professora sublinha e marca com asterisco todos esses verbos e, após o corpo do texto, deixa o seguinte bilhete:

Excerto VI

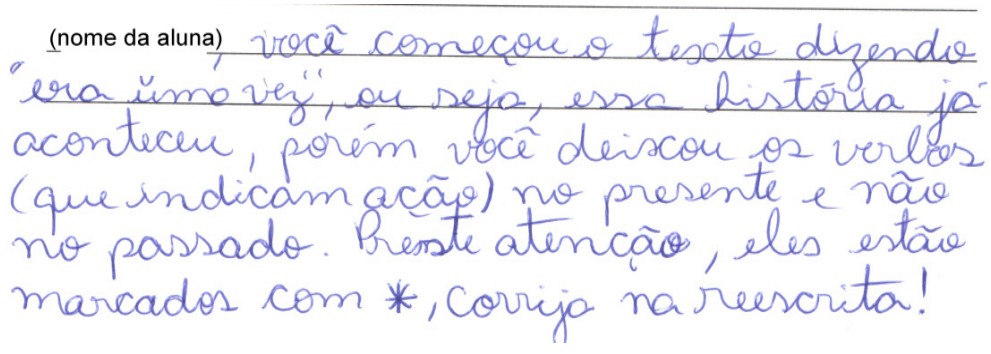

Ao contrário do comentário sobre pontuação deixado na primeira produção, este último parece ser muito mais elucidativo, pois explica como o aluno deveria proceder. Além disso, o apontamento do gênero é reforçado com correções indicativas, deixadas no corpo do texto. Na reescrita, o aluno E procura atender ao apontamento, mas alguns verbos marcados são deixados da mesma forma, o que pode indicar falta de atenção no momento da reescrita ou opção por não mudar determinados verbos. Segue a reescrita:

\section{Excerto VII}

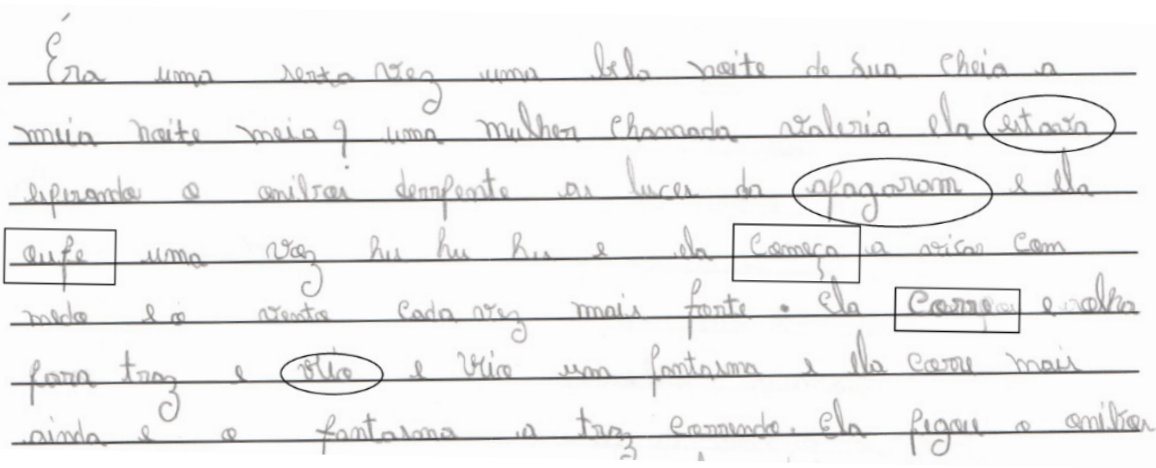

Para melhor visualização, foram marcados com retângulos os verbos cujos tempos não foram modificados pelo aluno, deixando-os no presente, e circulados os verbos que sofreram alterações a partir do apontamento do gênero. Embora haja oscilações no atendimento da orientação, identifica-se maior compreensão por parte do aluno e, consequentemente, maior nível de interação entre professor e aluno por meio da revisão. Destaca-se, ainda, que o apontamento do gênero, nesse caso, não visou apenas à correção na reescrita, mas a explicação ao aluno sobre a organização prototípica da narrativa, o que contribui para a apreensão do gênero.

Em relação as produções do Aluno $P$, a primeira delas apresenta dois comentários, sendo que ambos foram considerados apontamentos do gênero. O texto narra a brincadeira de dois irmãos que resultou na descoberta de uma passagem secreta. Logo no início, a professora apresenta um questionamento que chama a atenção para a caracterização dos personagens:

\section{Excerto VIII}

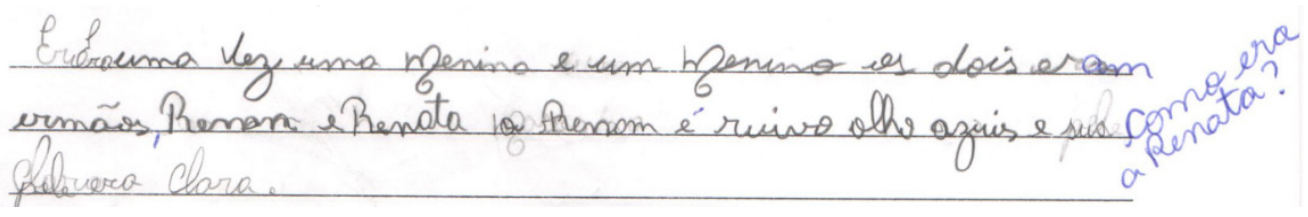

Mesmo tendo apresentado dois personagens, o aluno só descreve Renan, mas na reescrita atende à orientação e caracteriza Renata: 


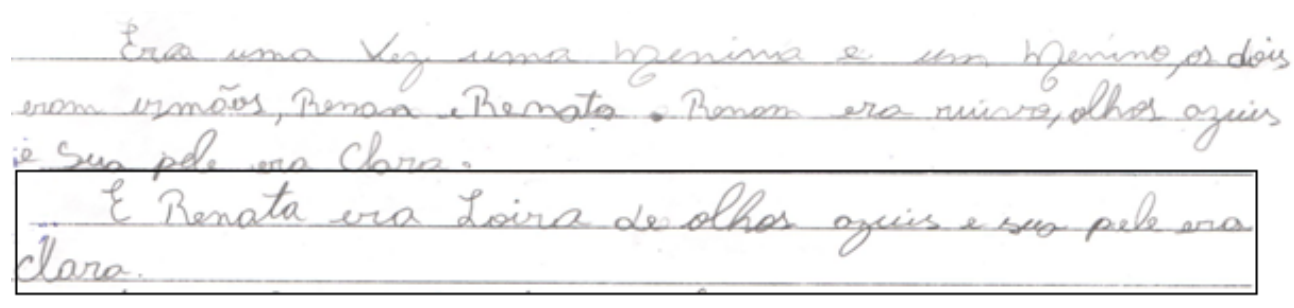

Dois aspectos devem ser ressaltados sobre a reescrita desse excerto. Ao atender ao apontamento, o aluno $P$ não consegue juntar as duas caracterizações, colocando-as até mesmo em parágrafos separados, ainda que os irmãos tenham praticamente as mesmas características descritas. Por outro lado, chama a atenção a capacidade do aluno de rever o próprio texto com relação à pontuação, considerando-se que são crianças do $4^{\circ}$ ano do Ensino Fundamental.

Na primeira versão não há nenhum apontamento que se refira aos sinais de pontuação. Mesmo assim, na reescrita ele acrescenta vírgulas em lugares que estavam faltando, como a localizada antes de "os dois irmãos", e troca a vírgula que havia depois de "Renan e Renata" por ponto, o que melhora a compreensão do texto ([...] os dois eram irmãos, Renan e Renata. Renan era ruivo [...]). Embora não sejam adequações específicas do gênero, as reformulações apresentam-se extremamente relevantes, pois revelam operações linguístico-discursivas que vão além dos apontamentos do professor (MENEGASSI, 1998), evidenciando uma marca do aluno como sujeito de seu próprio discurso.

O outro apontamento do gênero deixado na primeira produção foi relacionado à coerência da sequência narrativa. $\mathrm{O}$ aluno inicia contando que os dois irmãos estavam brincando, quando perceberam que o chão estava oco e começaram a cavar até encontrar uma passagem secreta. O texto continua e se encerra do seguinte modo:

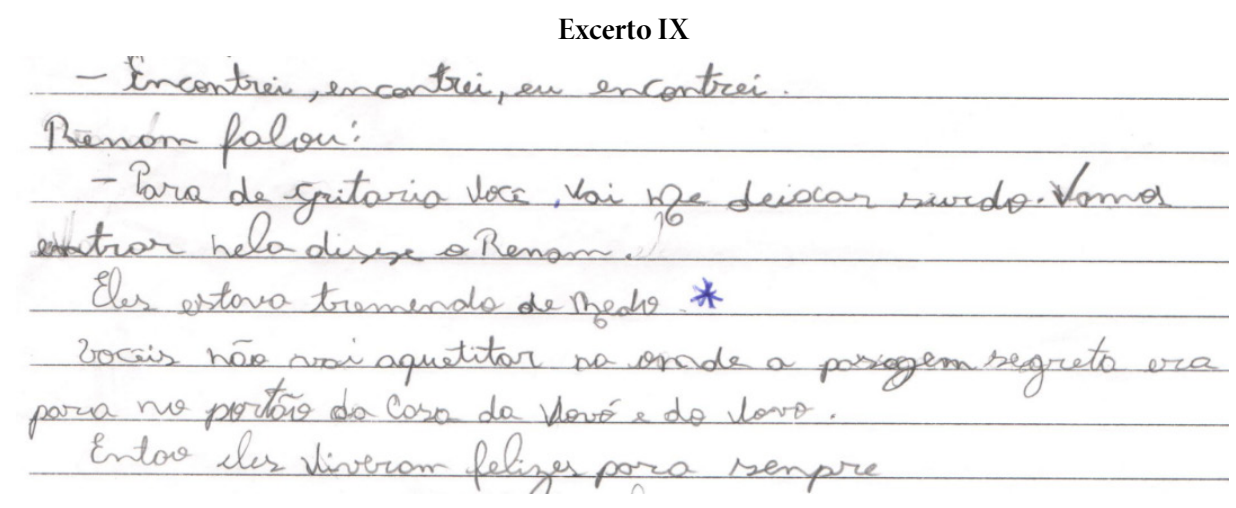

Com a leitura desse excerto, percebe-se que há uma ruptura na sequência narrativa. Diante disso, a professora apresenta as seguintes perguntas após o corpo do texto:

\section{Excerto X}

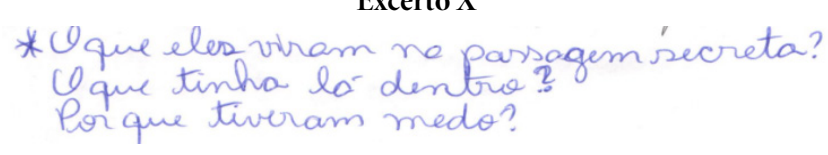

As perguntas procuram motivar o aluno a organizar melhor a narração do desfecho. Na reescrita não há grandes avanços com relação aos detalhes da história, mas os acréscimos mostram que o aluno compreendeu a orientação e buscou reformulações. Na sequência, a reescrita referente ao Excerto IX. Os acréscimos referentes ao apontamento estão sublinhados. 


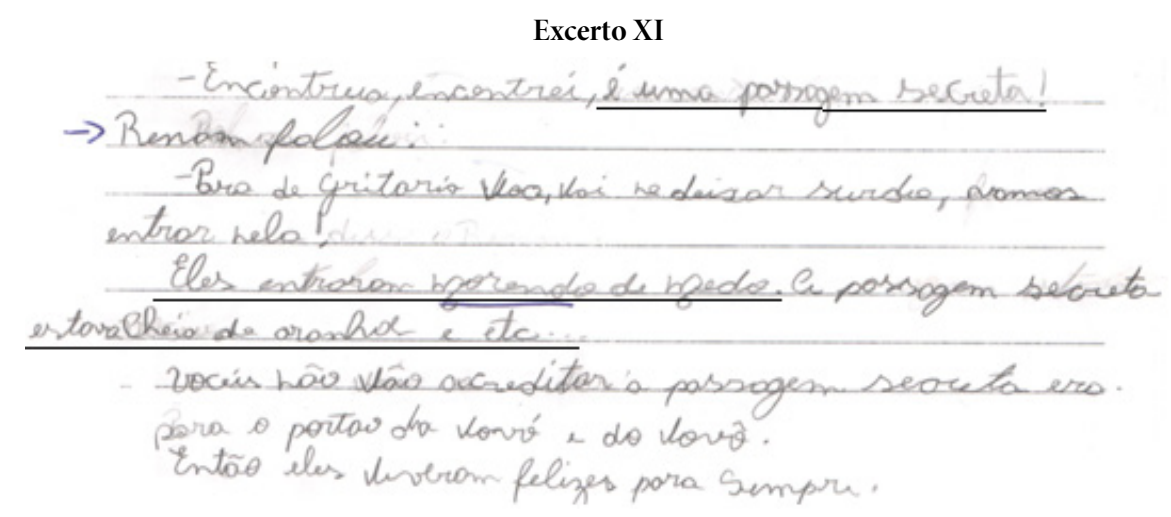

Na fala em que Renata grita "Encontrei", o aluno $P$ acrescenta que se trata da descoberta de uma passagem secreta, o que ainda não havia sido citado no texto. A narração que conta que os irmãos entraram morrendo de medo foi utilizada em substituição a "eles estava tremendo de medo". Essa troca, utilizando o verbo entrar, melhora a compreensão do leitor, pois antes não havia sido mencionado se eles passavam pelo lugar secreto. Atendendo ao apontamento do gênero que questiona o que havia na passagem, $\mathrm{o}$ aluno $P$ explica que havia aranhas.

Os apontamentos do gênero deixados nesse texto mostraram-se relevantes, pois foram atendidos e contribuíram para a melhor organização da Narrativa de Terror. É importante salientar que, para esse aluno, a reescrita já é um trabalho mais profícuo do que para o aluno $E$. Este apresenta dificuldades em compreender os apontamentos, faz poucas reformulações e de maneira parcial; já o aluno $P$ apresenta, na reescrita referente aos dois apontamentos, reformulações que mostram seu diálogo com o próprio discurso, pois vão além das orientações da professora. Na reescrita do Excerto $V$, por exemplo, o aluno $P$ faz outras reformulações, explicitadas no Quadro III.

\begin{tabular}{c|c} 
Texto I - Aluno $P$ & Reescrita Texto I - Aluno $P$ \\
\hline $\begin{array}{c}\text { Renan falou: } \\
\text { - Para de gritaria você, vai me deixar surdo. Vamos entrar nela disse } \\
\text { o Renan. }\end{array}$ & $\begin{array}{c}\text { Renan falou: } \\
\text { Vocêis não vai aquetitar na onde a passagem segreta era para o } \\
\text { portão da casa da Vovó e do Vovo. }\end{array}$ \\
\end{tabular}

Quadro 3: Reformulações extras do Aluno $P$

No primeiro trecho, ele percebe que não é necessário escrever "disse o Renan", pois isso já havia sido marcado antes da fala do personagem. Já no segundo trecho, o aluno percebe e corrige a concordância do verbo "ir", as grafias de "acreditar" e "secreta", e a acentuação de "Vovô".

A partir dos registros obtidos em todos os textos e da análise das produções dos alunos $E$ e $P$, fica explícita a relevância da prática da reescrita no ambiente escolar, pois o simples ato de devolver o texto ao aluno e pedir que o releia já pode indicar avanços no texto reescrito, como se observou nas reescritas do aluno $P$.

Quanto aos apontamentos construídos com vistas à organização do gênero textual produzido, percebeu-se que foi uma prática bastante adotada pela professora, o que demonstrou o valor do estudo teórico-metodológico desenvolvido junto à pesquisadora antes da prática em sala de aula. 
Nos apontamentos do gênero, demonstrou-se que sua abordagem pode ser explicativa, pois, ao mesmo tempo em que corrige, proporciona ao aluno à apreensão do gênero, como foi visto no bilhete que mencionou sobre o uso do tempo verbal. Outro aspecto notado foi que os apontamentos devem considerar a interação com o interlocutor, pois alguns deles parecem não ter sido atendidos por dificuldade de compreensão por parte do aluno, o que levaria a outra investigação diferente desta.

\section{CONSIDERAÇÕES FINAIS}

O desenvolvimento deste trabalho teórico-metodológico mostrou como a formação continuada é imprescindível para o professor. Embora a professora Ana não tivesse o hábito de praticar a reescrita com seus alunos, os encontros de estudo e de orientação com a pesquisadora a instrumentalizaram para a prática, como mostraram os excertos dos textos apresentados. Essa internalização da professora foi facilitada pelo motivo de ter-se abordado um gênero textual específico e, a partir dele, ter-se elaborado a unidade de ensino. Assim, ratifica-se que as orientações e que o acompanhamento com a docente são práticas necessárias no processo de formação continuada, como discutido em Gasparotto e Menegassi (2013).

Quanto aos alunos, contatou-se o aprimoramento no desenvolvimento da escrita, porém a pouca familiaridade com o processo de reescrita de textos pode ter afetado a compreensão dos apontamentos e o desempenho na reformulação, o que reforça visão de Menegassi (1998) de que a reescrita deve ser uma prática constante na escola, a ponto de ser considerada comum por professores e alunos.

A proposta de encaminhamento da reescrita, a partir do gênero Narrativa de Terror, apontou a necessidade de desenvolver e aprimorar estratégias próprias de revisão e reescrita caras ao gênero textual investigado, que auxiliam tanto na compreensão e organização do texto do aluno, quanto na apreensão das características do gênero. Isso acontece porque, ao considerar-se o gênero, consideram-se também as necessidades específicas do enunciado, que orientam o leitor para o objetivo comunicativo, o interlocutor e até mesmo o estilo a ser utilizado.

Como posto por Ruiz (2010), a pertinência da reescrita em situação de ensino, sobretudo de línguas, deve levar a uma prática cada vez mais constante no contexto escolar, pois a reflexão sobre o ato da escrita, proporcionada ao aluno por meio dos apontamentos, é uma prática que implica aprimoramentos em toda sua formação, não unicamente para a produção de textos, pois se trata de dialogar com o escrito e reconhecer-se como sujeito de seu próprio discurso (BAKHTIN, 2010).

\section{REFERÊNCIAS}

ACOSTA-PEREIRA, R.; RODRIGUES, R. H. Os gêneros do discurso sob perspectiva da Análise Dialógica de Discurso do Círculo de Bakhtin. In: Gêneros Discursivos \& Interfaces Teóricas. Revista Letras/Universidade Federal de Santa Maria - Programa de Pós Graduação em Letras - n.1, (jan./jun.1991). - Santa Maria, RS: PPGL, 1991-V. 20, N. 40 (jan./jun.2010). p. 147-162. Disponível em:<http://cascavel.ufsm.br/revistas/ojs-2.2.2/index.php/letras/article/view/12149>. Acesso em: 2 fev. 2015.

ACOSTA-PEREIRA, R. Contribuições dos estudos sobre gêneros do discurso para a análise linguística em sala de aula: perspectivas dialógicas. Revista Caminhos em Linguística Aplicada, Taubaté, v. 5, n. 2, p. 21-41, 2011. Disponível em:< http://periodicos.unitau.br/ojs-2.2/index.php/caminhoslinguistica/article/view/1349/990>. Acesso em: 15 jan. 2015.

ANTUNES, I.Aula de Português: encontro e interação. São Paulo: Parábola, 2003.

BAKHTIN, M. M. Marxismo e filosofia da linguagem. 12. ed. São Paulo: Hucitec, 2010.

BAKHTIN, M. Estética da criação verbal. 4. ed. São Paulo, Martins Fontes, 2009. 
BRAIT, B. Análise e teoria do discurso. In: BRAIT, B. Bakhtin: outros conceitos-chave. São Paulo: Contexto, 2000, p. 9-31.

Construção coletiva da perspectiva dialógica: história e alcance teórico-metodológico. In: FÍGARO, R. (Org.). Comunicação e análise do discurso. São Paulo: Contexto, 2012, v. 1. p. 79-98.

BRASIL. Secretaria de Ensino Fundamental. Parâmetros Curriculares Nacionais: Língua Portuguesa: $5^{a}$ a 8ª séries. Brasília: SEF, 1998.

COSTA, M. M. Metodologia do ensino da Literatura Infantil. Curitiba: Ibpex, 2007.

COSTA-VAL, M. da G. et al. Avaliação do texto escolar: professor-leitor/ aluno-autor. Belo Horizonte: Autêntica Editora, 2009.

ESPER, D. S. Caracterizando os processos de revisão e reescrita no Ensino Fundamental I. 2011. 73 f. Relatório de Pesquisa. Departamento de Letras, Universidade Estadual de Maringá, Maringá, 2011.

FABRE, C. La reecriture dans l'ecriture: le cas des ajouts dans les écrits scolaires. Études de Linguistique Appliquée, n. 68, p. 15-39, 1987.

FIAD, R. S.; MAYRINK-SABINSON, M. L. T. A escrita como trabalho. São Paulo: Contexto, 1991.

. Episódios de reescrita em textos infantis. Estudos Linguísticos, Araraquara, v. 38, fac. 2, p. 9-18, 2009.

FUZA, A. F; MENEGASSI, R. J. Revisão e reescrita de textos a partir do gênero textual conto infantil. Diálogo das Letras, Pau dos Ferros, v. 1, n. 1, p. 41-56, jan./jun. 2012.

GARCEZ, L. H. C. A escrita e o outro: os modos de participação na construção do texto. Brasília: Editora Universidade de Brasília, 1998.

GARCIA, M. O. Comunicação em prosa moderna: aprenda a escrever, aprendendo a pensar. 26. ed. Rio de Janeiro: FGV, 2007.

GASPAROTTO, D. M. MENEGASSI, R. J. A mediação do professor na revisão e reescrita de textos de aluno de Ensino Médio. Revista Calidoscópio, v. 11, n. 1, p. 29-43, 2013.

GERALDI, J. W. Linguagem e ensino: exercícios de militância e divulgação. Campinas: ALB/Mercado de Letras, 1996.

. Da redação à produção de textos. In: GERALDI, J. W.; CITELLI, B. (Org.). Aprender e ensinar com textos de alunos. vol. I. São Paulo: Cortez, 2001.p. 17-23.

JESUS, C. A. Reescrevendo o texto: a higienização da escrita. In: CHIAPPINI, L. Aprender e ensinar com textos de alunos. v.1. São Paulo: Cortez, 2001.p. 99-117.

LEAL, L. de F. V. A formação do produtor de texto escrito na escola: uma análise das relações entre os processos interlocutivos e os processos de ensino. In: COSTA-VAL, M. da G. (Org.). Reflexões sobre práticas escolares de produção de texto. Belo Horizonte: Autêntica/CEALE/FaE/UFMG, 2003.p. 53-67.

MENEGASSI, R. J. Da revisão à reescrita: operações e níveis lingüísticos na construção do texto. 1998. 263f. Tese (Doutorado) Faculdade de Ciências e Letras de Assis, Universidade Estadual Paulista, Assis, 1998.

. Comentários de revisão na reescritura de textos: componentes básicos. Trabalhos em Linguística Aplicada, Campinas, $\mathrm{n}$.

35 , p. 84-93, 2000.

Forum linguistic., Florianópolis, v.12, n.3, p.808-826, jul./set.2015 
MENEGASSI, R. J. O processo de produção textual. In: SANTOS, A. R.; GREGO, E. A.; GUIMARÃES, T. B. (Org.). A produção textual e o ensino. Maringá, PR: Eduem, 2010. p. 75-102.

Conceitos bakhtinianos na prova de redação. Revista Linguas e Letras. Ed. Especial XIX CELLIP, primeiro semestre de 2011. Disponível em: <http://e-revista.unioeste.br/index.php/linguaseletras/article/view/5487>. Acesso em: $10 \mathrm{dez} .2014$.

. A revisão de textos na formação docente inicial. In: GONÇALVES, A. V.; BAZARIM, M. Interação, gêneros e letramento: a (re)escrita em foco. 2. ed. Campinas: Pontes, 2013. p. 105-131.

MOTERANI, N. G. A reescrita de textos nas $7^{a}$ e $8^{a}$ séries do ensino fundamental: caracterização de aspectos linguístico-discursivos. 2012. 164f. Dissertação (Mestrado em Letras) - Programa de pós graduação em Letras, Universidade Estadual de Maringá, Maringá, 2012.

RUIZ, E. D. Como corrigir redações na escola. São Paulo, Contexto, 2012.

ROCHA, G. O papel da revisão na apropriação de habilidades textuais pela criança. In: VAL, M. da G.C.; ROCHA, G. (Org.). Reflexões sobre práticas escolares de produção de texto: o sujeito-autor. Belo Horizonte: Autêntica, 2003. p. 69-83.

ROJO, R. (Org.). A prática de linguagem em sala de aula: praticando os PCNs. São Paulo: EDUC; Campinas: Mercado de Letras, 2008.

SERAFINI, M. T. Como escrever textos. Trad. Maria Augusta de Matos. Adap. Ana Maria Marcondes Garcia. 12. ed. São Paulo: Globo, 2004.

SERCUNDES, Maria M. I. Ensinando a escrever: as práticas em sala de aula. In: GERALDI, J. W.; CITELLI, B. (Coord.). Aprender e ensinar com textos de alunos. São Paulo: Cortez, 2011. p. 79-100.

Recebido em 09 / 07 / 2015. Aprovado em 13 / 08 / 2015. 